Laxmisha Rai

Programming in $\mathrm{C}++$ 


\section{Information and Computer Engineering}

\section{Volume 5}

\section{Already published in the series}

\section{Volume 4}

Shuqin Lou, Chunling Yan, Digital Electronic Circuits, 2018

ISBN 978-3-11-061466-4, e-ISBN 978-3-11-061491-6, e-ISBN (EPUB) 978-3-11-061493-0

\section{Volume 3}

Baolong Guo, Signals and Systems, 2018

ISBN 978-3-11-059541-3, e-ISBN 978-3-11-059390-7, e-ISBN (EPUB) 978-3-11-059296-2

\section{Volume 2}

Jie Yang, Congfeng Liu, Random Signal Analysis, 2018

ISBN 978-3-11-059536-9, e-ISBN 978-3-11-059380-8, e-ISBN (EPUB) 978-3-11-059297-9

\section{Volume 1}

Beija Ning, Analog Electronic Circuit, 2018

ISBN 978-3-11-059540-6, e-ISBN 978-3-11-059386-0, e-ISBN (EPUB) 978-3-11-059319-8 


\section{Laxmisha Rai}

\section{Programming in $\mathrm{C}++$}

Object-Oriented Features

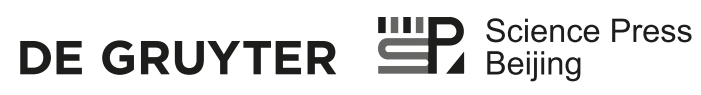




\section{Author}

\section{Laxmisha Rai}

College of Electronic and Information Engineering Shandong University of Science and Technology, Qingdao, China.

ISBN 978-3-11-059539-0

e-ISBN (PDF) 978-3-11-059384-6

e-ISBN (EPUB) 978-3-11-059295-5

ISSN 2570-1614

Library of Congress Control Number: 2018954463

\section{Bibliographic information published by the Deutsche Nationalbibliothek}

The Deutsche Nationalbibliothek lists this publication in the Deutsche Nationalbibliografie; detailed bibliographic data are available on the Internet at http://dnb.dnb.de.

(C) 2019 Walter de Gruyter GmbH, Berlin/Boston, Science Press

Typesetting: Integra Software Services Pvt. Ltd.

Printing and binding: CPI books $\mathrm{GmbH}$, Leck

Cover image: Prill/iStock/Getty Images Plus

www.degruyter.com 